\title{
ACIDENTES COM MOTORISTAS NO TRANSPORTE RODOVIÁRIO DE PRODUTOS PERIGOSOS
}

\author{
Carlos Eugenio de Carvalho Ferreira
}

\begin{abstract}
Resumo: Pesquisa recente da Fundação Seade analisou as informações dos boletins de ocorrência de 1.622 acidentes de transporte com produtos perigosos, registrados entre 1997 e 1999. Os registros de acidentes envolvendo o transporte rodoviário de produtos perigosos foram localizados no espaço geográfico, em uma base georreferenciada, com a finalidade de se identificar as principais concentrações espaciais desses acidentes. Palavras-chave: produtos perigosos; acidentes rodoviários; acidentes com motoristas.
\end{abstract}

Abstract: A recent study by the Fundação Seade analyzed 1,622 accident reports involving the highway transport of dangerous products between 1997 and 1999. These records were sorted geographically in order to identify where most of these accidents were concentrated.

Key words: dangerous products; highway accidents; accidents with drivers.

$\mathrm{O}$ s acidentes no transporte rodoviário de produtos perigosos adquirem uma importância especial, uma vez que a intensidade de risco está associada à periculosidade do produto transportado. Considera-se produto perigoso aquele que representa risco para as pessoas, para a segurança pública ou para o meio ambiente, ou seja, produtos inflamáveis, explosivos, corrosivos, tóxicos, radioativos e outros produtos químicos que, embora não apresentem risco iminente, podem, em caso de acidentes, representar uma grave ameaça à população e ao meio ambiente. Os acidentes no transporte desses produtos podem ter conseqüências catastróficas, sobretudo diante da proximidade de cidades e de populações lindeiras às principais rodovias. Além das perdas humanas de valor social incalculável, os custos decorrentes da contaminação ambiental atingem cifras muito elevadas.

Pesquisa recente da Fundação Seade, em parceria com a Fundacentro/Ministério do Trabalho e Emprego e o Denatran/Ministério da Justiça, analisou as informações dos boletins de ocorrência de 1.622 acidentes de transporte com produtos perigosos, registrados pe- las Polícias Rodoviárias Estadual e Federal do Estado de São Paulo, entre 1997 e 1999.

Os registros de acidentes envolvendo o transporte rodoviário de produtos perigosos foram localizados no espaço geográfico, em uma base georreferenciada, com a finalidade de se identificar as principais concentrações espaciais desses acidentes. Também foram evidenciadas algumas características relacionadas com as ocorrências, destacando-se os acidentes graves e fatais dos condutores de veículos.

Foram pesquisadas também outras fontes de dados como a Relação Anual de Informações Sociais - Rais, do Ministério do Trabalho e Emprego, e as Comunicações de Acidentes do Trabalho - CATs do Instituto Nacional de Seguridade Social - INSS (Pesquisa de Acidentes do Trabalho de Motoristas e Cobradores, através das Informações Detalhadas das CATs, desenvolvida pela Fundação Seade em parceria com a Fundacentro/Ministério do Trabalho e Emprego e o Denatran/ Ministério da Justiça).

Trata-se de uma análise descritiva que traz à tona elementos que podem contribuir para prevenção desses acidentes. 


\section{INCIDÊNCIA DE ACIDENTES NAS RODOVIAS PAULISTAS}

Conforme verificado nos registros de ocorrências da Polícia Rodoviária Estadual, houve um total de 1.563 acidentes durante o transporte de produtos perigosos nas rodovias do Estado de São Paulo, no período de 1997 a 1999, sendo 487 em 1997, 510 em 1998 e 566 em 1999. Nas rodovias federais foram registrados 23 acidentes em 1998 e 36 em 1999. Essas cifras revelam uma tendência crescente dos acidentes rodoviários no transporte de produtos perigosos. Nas rodovias estaduais, cerca de $60 \%$ dos acidentes foram registrados em dez rodovias e $32 \%$ em somente três - SP 330 (Via Anhangüera), SP 332 (General Milton Tavares de Souza) e SP 310 (Washington Luiz). Os acidentes nas rodovias federais que cruzam o Estado concentraram-se nas três principais: BR 381 (Fernão Dias), BR 116 (Via Dutra e Régis Bittencourt) e BR 153 (Transbrasiliana).

A média anual de acidentes por rodovia, representada no Gráfico 1, permite uma comparação mais adequada entre as rodovias estaduais e federais, considerando-se que os períodos de referência são distintos. Ficam evidentes as grandes diferenças das médias anuais de acidentes por rodovia estadual e federal. Tais diferenças refletem, por um

TABELA 1

Acidentes no Transporte de Produtos Perigosos, segundo as Principais Rodovias Estaduais e Federais

Estado de São Paulo - 1997-1999

\begin{tabular}{lr}
\hline Principais Rodovias & $\%$ \\
\hline Rodovias Estaduais (1997-99) & 100,00 \\
SP 330 (Via Anhangüera) & 15,55 \\
SP 332 (Gen. Milton Tavares de Souza) & 8,83 \\
SP 310 (Washington Luiz) & 8,00 \\
SP 270 (Raposo Tavares) & 4,54 \\
SP 150 (Via Anchieta) & 4,29 \\
SP 300 (Via Rondon) & 4,29 \\
SP 304 (Luiz de Queiroz) & 4,09 \\
SP 225 (Eng. Paulo Nilo Coelho) & 3,45 \\
SP 280 (Pres. Castello Branco) & 3,45 \\
SP 348 (Rod. Bandeirantes) & 3,33 \\
Demais & 40,18 \\
Rodovias Federais (1998-99) & 100,00 \\
BR 381 (Fernão Dias) & 45,76 \\
BR 116 (Via Dutra, Régis Bittencourt) & 40,68 \\
BR 153 (Transbrasiliana) & 13,56 \\
\hline
\end{tabular}

Fonte: Polícias Rodoviárias Estadual e Federal; Fundação Seade. lado, a intensidade do tráfego de veículos transportando produtos perigosos e, por outro, os fatores de risco de acidentes atuando na rodovia.

A malha rodoviária do Estado considera que, na rodovia codificada com número ímpar, um veículo estará circundando a capital a uma distância aproximada, em quilômetros, igual ao próprio número da rodovia. Na rodovia com o número par, o veículo estará se afastando ou se aproximando da capital. A maior ocorrência de acidentes foi verificada nesses grandes eixos com numeração par, que se destacam pela extensão e por constituírem as grandes rotas de transporte dos produtos perigosos para o interior paulista ou mesmo para além das fronteiras do Estado.

A Via Anhangüera destaca-se pela elevada freqüência de acidentes, com média anual de 81 acidentes no período 1997-99, representando, assim, quase sete acidentes por mês. As rodovias Milton Tavares de Souza e Washington Luiz apresentaram média anual de acidentes de 46 e

\section{GRÁFICO 1}

Média Anual de Acidentes no Transporte de Produtos Perigosos nas Principais Rodovias Estaduais e Federais Estado de São Paulo - 1997/1999

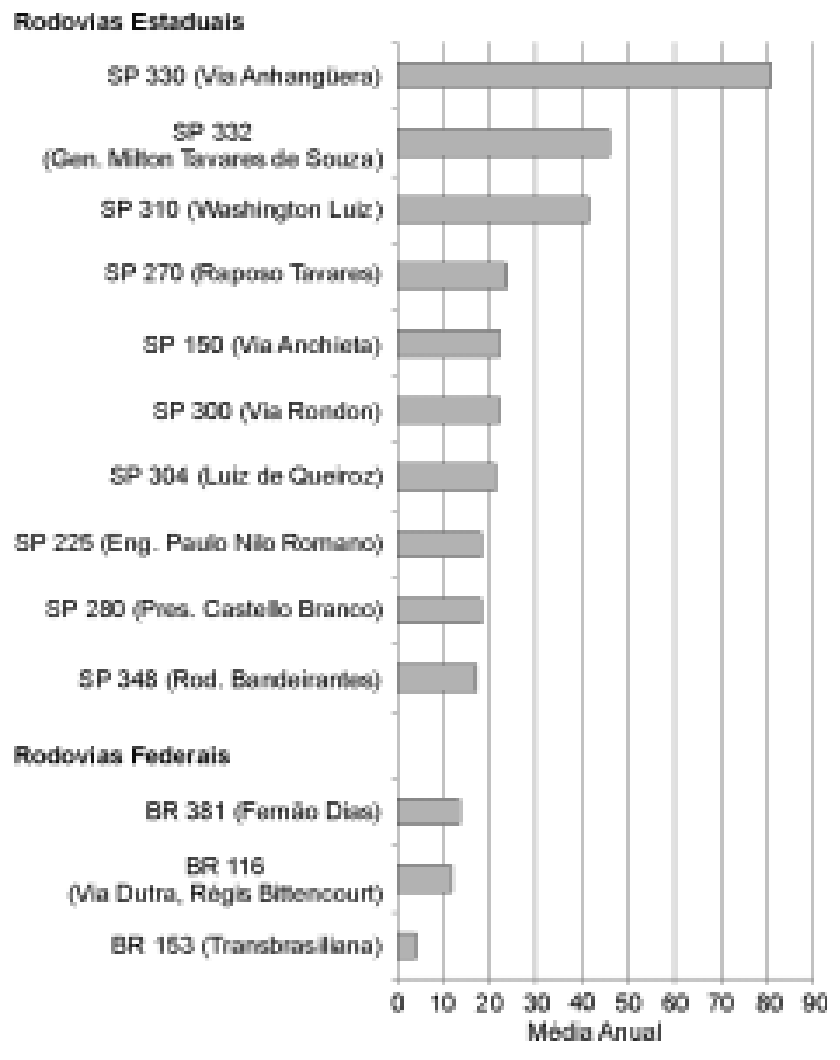

Fonte: Polícias Rodoviárias Estadual e Federal. 
42 ocorrências respectivamente, significando quase quatro acidentes por mês nessas rodovias.

Constata-se também uma grande diferença na distribuição dos acidentes no interior de cada rodovia isoladamente. Essas diferenças podem ser observadas nos trechos rodoviários delimitados pelas fronteiras dos municípios. As maiores médias anuais de ocorrências de acidentes foram constatadas nos trechos rodoviários da SP 332 (General Milton Tavares de Souza), município de Paulínia (23,67 acidentes anuais) e Cosmópolis (10,67); da SP 330 (Via Anhangüera), município de Limeira (17,67); e da SP 150 (Via Anchieta), município de São Bernardo do Campo $(10,67)$ e Cubatão $(9,67)$. Em seguida, destaca-se o trecho rodoviário da BR 381 (Fernão Dias), município de Mairiporã $(7,50)$, de jurisdição federal. A média de acidentes nesses municípios, somente dos trechos rodoviários mencionados, representa cerca de $15 \%$ do valor correspondente a todo o Estado de São Paulo. Esses resultados são decisivos no número total de acidentes registrados nos municípios. Assim, analisando-se a distribuição dos acidentes por município, verificou-se que os municípios do Estado de São Paulo que concentraram o maior número de acidentes foram: Paulínia (72 acidentes), Limeira (72), Campinas (71), São Bernardo do Campo (53), Cubatão (46) e Cosmópolis (36).

A localização de uma refinaria de grande porte, em Paulínia, é decisiva na explicação do intenso movimento de transporte de produtos químicos na região, da mesma forma que o complexo químico do município de Cubatão justifica o intenso movimento de transporte desses produtos neste município e em São Bernardo do Campo. A concentração de acidentes em tais regiões está diretamente associada ao intenso fluxo de veículos de carga somado ao fluxo, não menos intenso, de automóveis e outros veículos. Outros fatores de risco que agravam esse quadro estão relacionados com as condições das rodovias, a segurança dos veículos de carga e o perfil profissional do condutor.

\section{PONTOS DE CONCENTRAÇÃO DOS ACIDENTES COM PRODUTOS PERIGOSOS}

A análise anterior demonstrou a existência de grandes concentrações de acidentes segundo as rodovias e os trechos de rodovias delimitados pelas fronteiras dos municípios. Trata-se, agora, de refinar a identificação desses acidentes recorrendo-se a um procedimento metodológico que leve em conta o quilômetro da rodovia onde ocorreu o acidente. Essa informação começou a ser coletada pela Polícia Rodoviária a partir de 1998 e procurou-se analisála para o biênio 1998-99.

Foram construídos gráficos para as principais rodovias, assinalando-se o número de acidentes ocorridos em cada dez quilômetros, tornando-se mais visíveis as concentrações de acidentes ao longo da rodovia (Gráfico 2).

A análise dos gráficos demonstra que os acidentes se distribuem de forma muito diferenciada no interior de cada rodovia, com concentrações que variam significativamente em intensidade. A SP 332 (General Milton Tavares de Souza) apresenta o maior pico de concentração de acidentes, localizado entre os quilômetros 130 e 140, com mais de 35 acidentes em dois anos de observação. A frequiência de acidentes começa a aumentar a partir do quilômetro 110 e se reduz sensivelmente depois do quilômetro 150 .

Do início da rodovia até o quilômetro 100 , praticamente não foram registrados acidentes no transporte de produtos perigosos, no período analisado. Nos 50 quilômetros seguintes verificam-se as maiores incidências de acidentes do Estado para, em seguida, cair a níveis baixos, até o fim da rodovia. Esse trecho de 50 quilômetros situa-se, aproximadamente, entre o trevo de cruzamento com a Rodovia Dom Pedro I, em Campinas, e a cidade de Cosmópolis. Trata-se do principal acesso à maior refinaria do país, a Replan (Refinaria de Paulínia). A Rodovia General Milton Tavares de Souza (SP 332) apresenta um volume médio diário de veículos muito intenso, em grande parte constituído pelo transporte de produtos perigosos, representando uma das maiores concentrações de tráfego comercial da malha rodoviária do Estado. O elevado número de acidentes nessa estrada suscitou intervenções para melhorar as condições do tráfego, incluindo obras de recuperação, recapeamento, conexões, sinalização, etc. e projetos de duplicação de trechos mais críticos. Cabe destacar a construção de um estacionamento, no final da década de 90, para os veículos de transporte que se destinam à refinaria, o que contribuiu para racionalizar o fluxo de entrada e saída de veículos nas instalações industriais e evitar o estacionamento irregular nos acostamentos. Os resultados dessas iniciativas deverão se refletir nas estatísticas de acidentes mais recentes (após 1999).

A localização de refinarias e outras instalações industriais químicas e petroquímicas nas Regiões Metropolitanas de Campinas, da Baixada Santista e de São Paulo, que representam a maior concentração populacional do país, alimenta o intenso fluxo de veículos transportando produtos perigosos que disputam, com outros veículos de 
Acidentes com Motoristas no Transporte Rodoviário DE..

carga, de passageiros, de passeio, etc., o espaço rodoviário que se torna relativamente escasso nas principais vias de acesso aos centros urbanos. Além disso, somam-se os fatores de risco agravantes, relacionados às condições das estradas, às condições da frota de veículos, ao preparo dos condutores, etc. Considerando que o sistema de transporte no Brasil é principalmente rodoviário, as questões de adequação da malha rodoviária e o estudo de rotas alternativas para o transporte de produtos perigosos são cruciais em regiões densamente povoadas.

Várias concentrações de acidentes também foram observadas em outras rodovias, tais como na Via Anchieta, quilômetros 40 a 49; na Via Anhangüera, com vários picos importantes; na Fernão Dias, quilômetros 60 a 69; etc. Outras rodovias, entretanto, apresentam um comportamento mais homogêneo na distribuição dos acidentes, como a SP 280 (Pres. Castello Branco) que registra casos ao longo de toda a sua extensão, porém com freqüência relativamente baixa. Em síntese, as curvas construídas com as informações dos acidentes, segundo o local da ocorrência em quilômetros, dão uma idéia clara dos padrões diferenciados de concentração dos acidentes e constituem um ponto de referência valioso para pesquisas mais aprofundadas sobre os fatores determinantes envolvidos com o problema (Gráfico 2).

\section{CLASSIFICAÇÃO DOS PRODUTOS PERIGOSOS TRANSPORTADOS NAS RODOVIAS}

Entre as informações coletadas pelo policiamento rodoviário na ocorrência de um acidente envolvendo um veículo que transporta produtos perigosos, consta a especificação do produto através do código de identificação da Classificação Internacional de Produtos Perigosos adotado pelas Nações Unidas, conhecido também como o "Número da ONU". A informação sobre os produtos tem um caráter prioritário para o atendimento, no caso de um acidente. As conseqüências dos acidentes no transporte desses materiais podem assumir dimensões catastróficas quanto ao número de vítimas, aos danos causados ao meio ambiente e aos elevados custos direta e indiretamente envolvidos. Além da documentação exigida por lei - que inclui a comprovação do treinamento do motorista, a ficha de emergência do produto e o manual de emergências -, a legislação brasileira determina que a unidade de transporte deve identificar o produto transportado através de painéis de segurança e rótulos de risco, segundo os padrões previstos de tamanho, cor e local de fixação no veículo (De-
TABELA 2

Acidentes no Transporte de Produtos Perigosos Ocorridos nas Rodovias Estaduais, segundo Classes do Produto Transportado Estado de São Paulo - 1997-1999

\begin{tabular}{lr}
\hline Classes do Produto Transportado & $\%$ \\
\hline Total & 100,00 \\
Gases inflamáveis & 8,32 \\
Gases comprimidos não tóxicos e não inflamáveis & 1,66 \\
Gases tóxicos por inalação & 1,92 \\
Líquidos inflamáveis & 57,01 \\
Sólidos inflamáveis & 0,64 \\
Substâncias passíveis de combustão espontânea & 0,13 \\
Substâncias que, em contato com a água, emitem gases inflamáveis & 0,13 \\
Substâncias oxidantes & 0,58 \\
Substâncias tóxicas & 1,15 \\
Substâncias corrosivas & 11,71 \\
Substâncias perigosas diversas & 2,82 \\
lgnorado & 13,95 \\
\hline
\end{tabular}

Fonte: Polícia Militar Rodoviária Estadual; Fundação Seade.

creto n 96.044 , de 18 de maio de 1988, e Portaria n. 204, de 20 de maio de 1997, do Ministério dos Transportes).

O sistema internacional de classificação dos produtos perigosos considera nove classes de risco e a classificação dos materiais identificados nos acidentes foi realizada com base na tabela dos produtos que consta do Manual de Emergências, editado pela Associação Brasileira da Indústria Química - Abiquim.

Cada registro de acidente do banco de dados foi recodificado com o número da classe de risco constante na tabela do referido manual. Dessa forma, tornou-se possível agrupar os produtos por classes de risco da ONU.

A Tabela 2 mostra que, entre os principais produtos transportados e associados com algum acidente, 57,01\% estão relacionados com transporte de líquidos inflamáveis, $11,71 \%$ com substâncias corrosivas e 8,32\% com gases inflamáveis.

\section{OS RISCOS PARA AS POPULAÇÕES LINDEIRAS E PARA O MEIO AMBIENTE}

Os riscos de acidentes no transporte rodoviário de produtos perigosos adquirem importância vital para as populações lindeiras. Considerando que muitas aglomerações se desenvolveram às margens das estradas e, de certa forma, tiveram seu crescimento demográfico influenciado pelo movimento das rodovias, é muito significativo o risco dos acidentes para as populações expostas nas proximidades das estradas. Existem muitos casos em que a rodovia principal corta a cidade e a ocorrência de aci- 


\section{GRÁFICO 2}

Padrões de Concentração de Acidentes no Transporte Rodoviário de Produtos Perigosos, segundo Localização (Km) na Rodovia Estado de São Paulo - 1998-1999

SP-332 (General Milton Tavares de Souza)

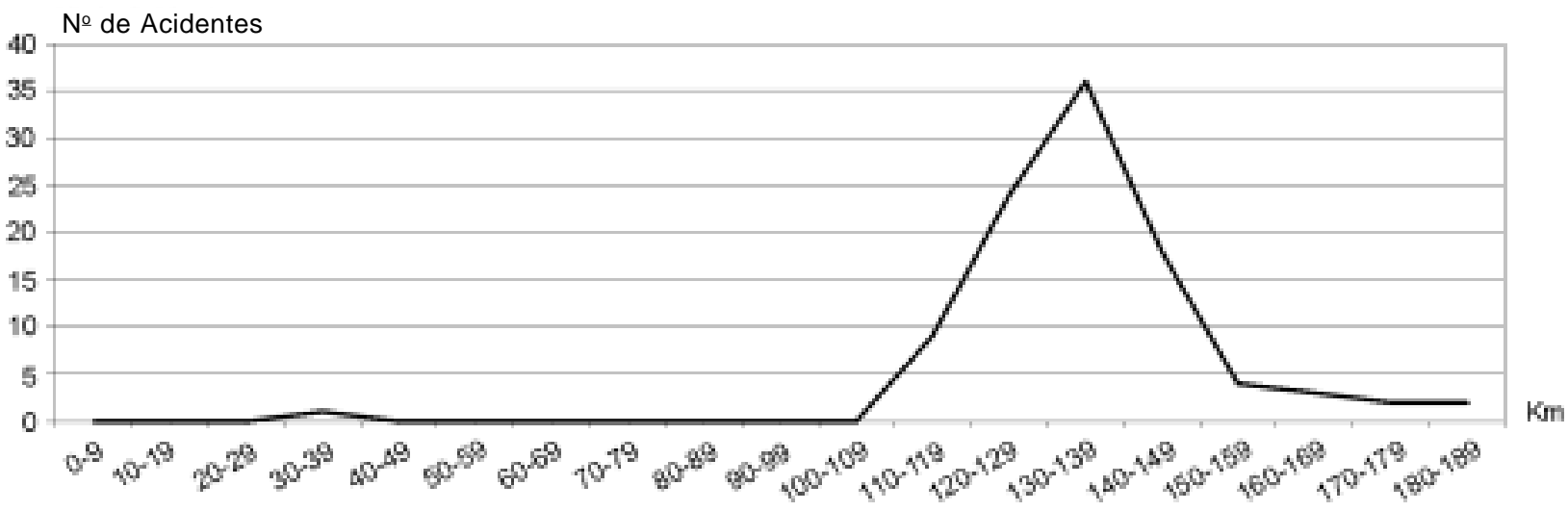

BR-381 (Fernão Dias)

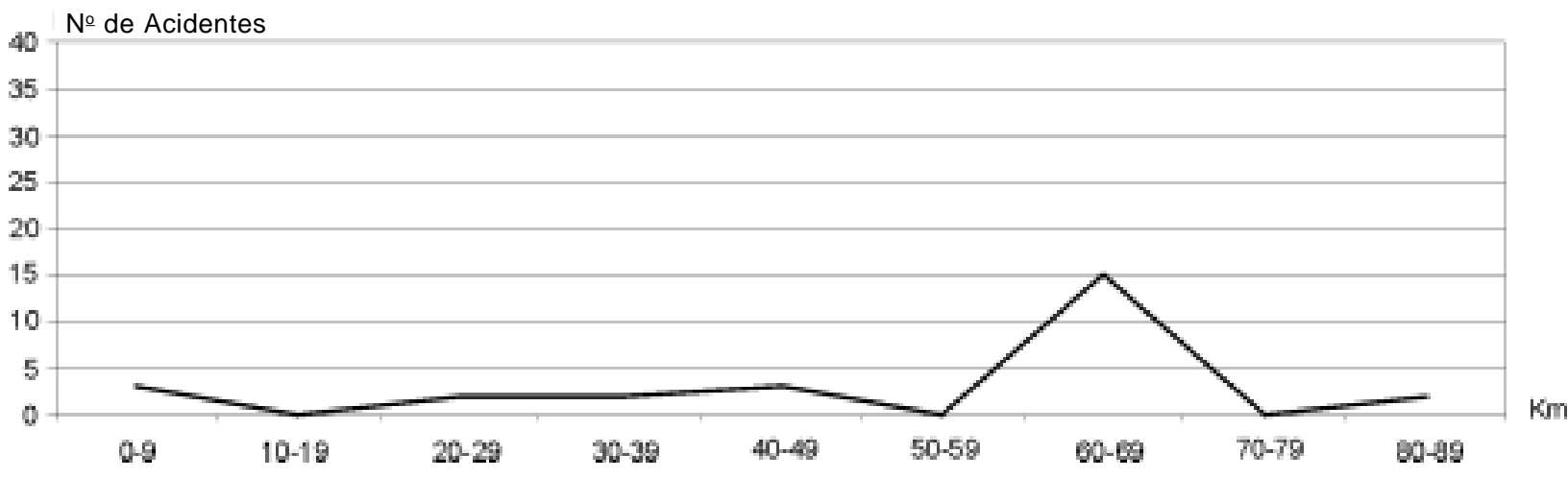

SP-310 (Washington Luiz)

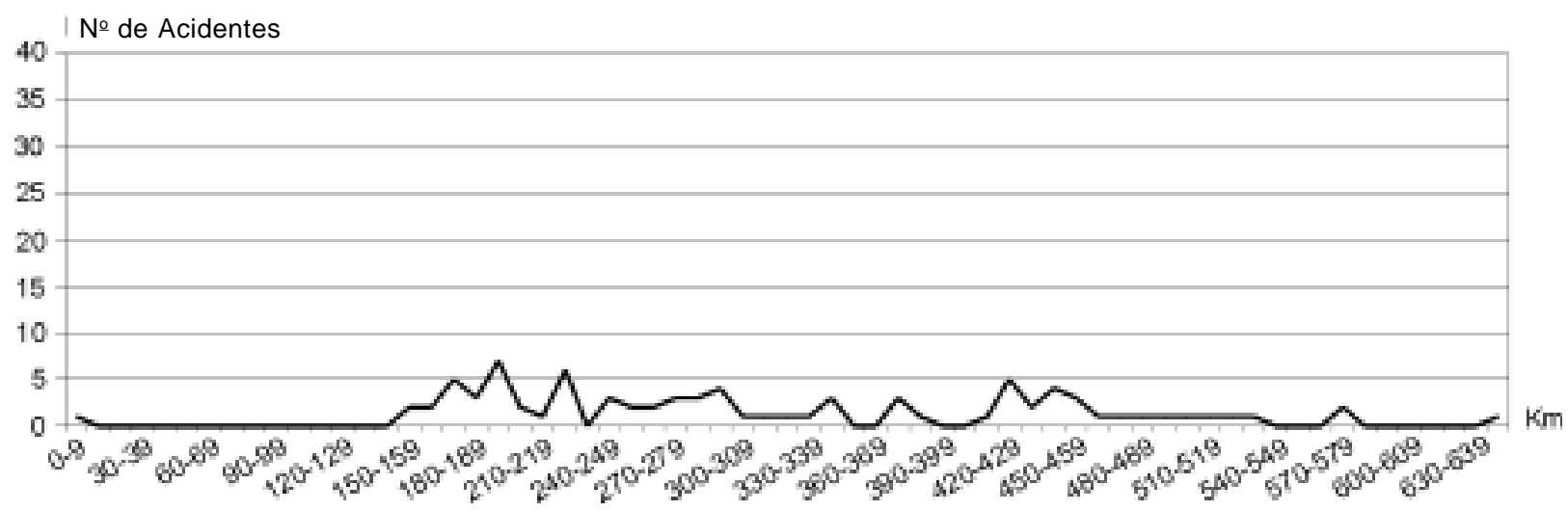


GRÁFICO 2

Padrões de Concentração de Acidentes no Transporte Rodoviário de Produtos Perigosos, segundo Localização (Km) na Rodovia Estado de São Paulo - 1998-1999

\section{SP-150 (Via Anchieta)}

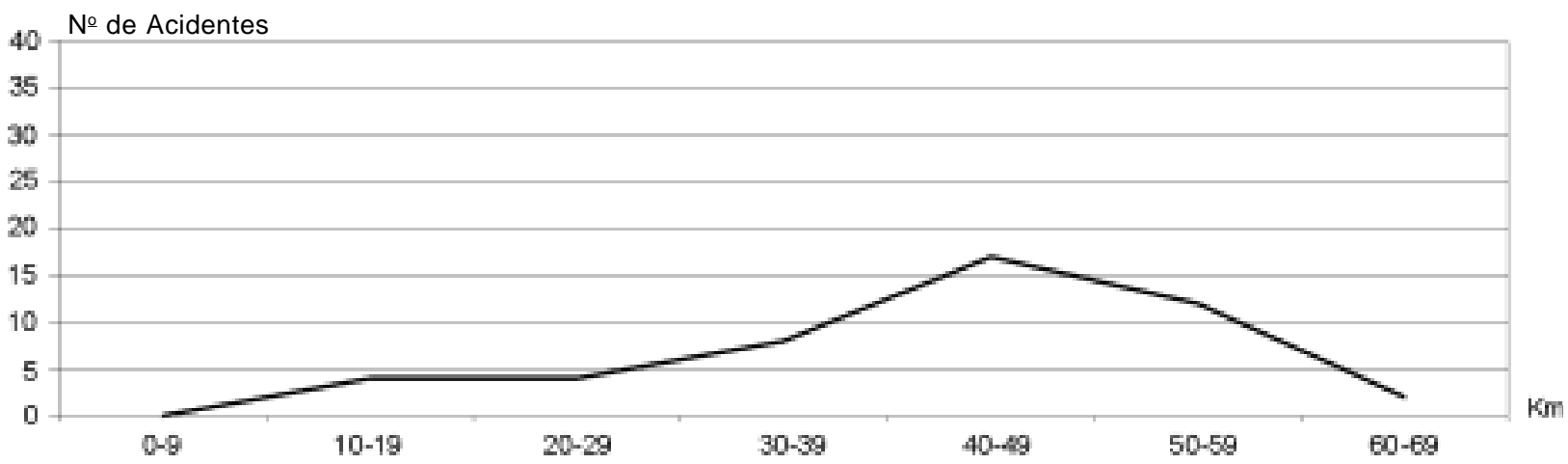

SP-330 (Via Anhangüera)

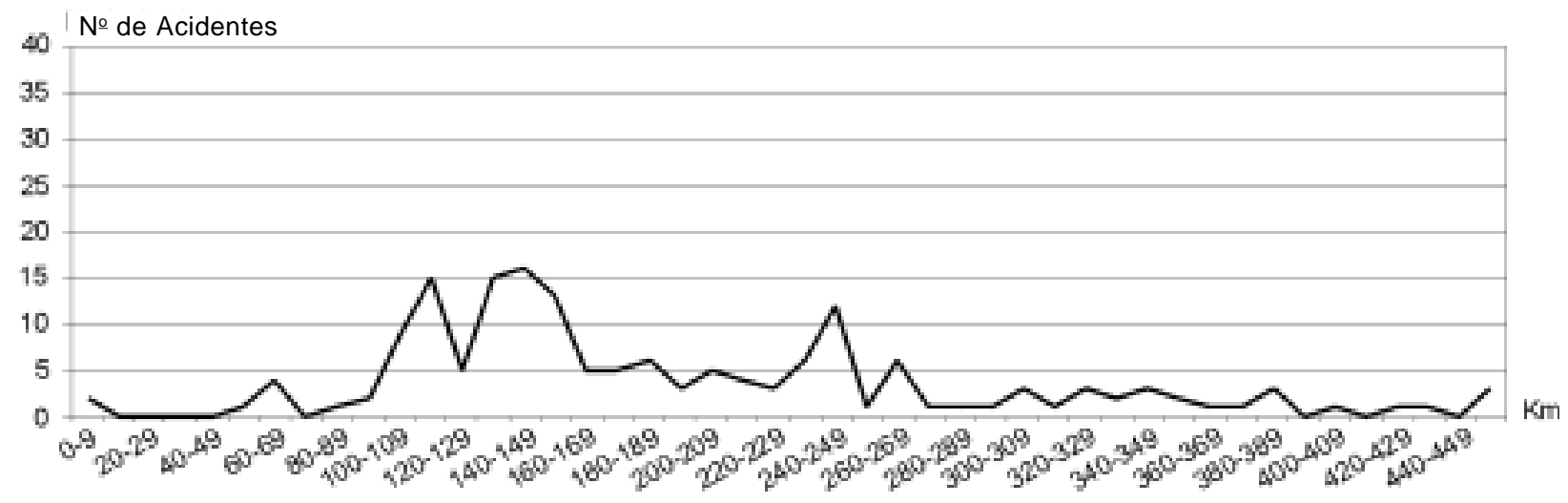

SP-280 (Pres. Castello Branco)

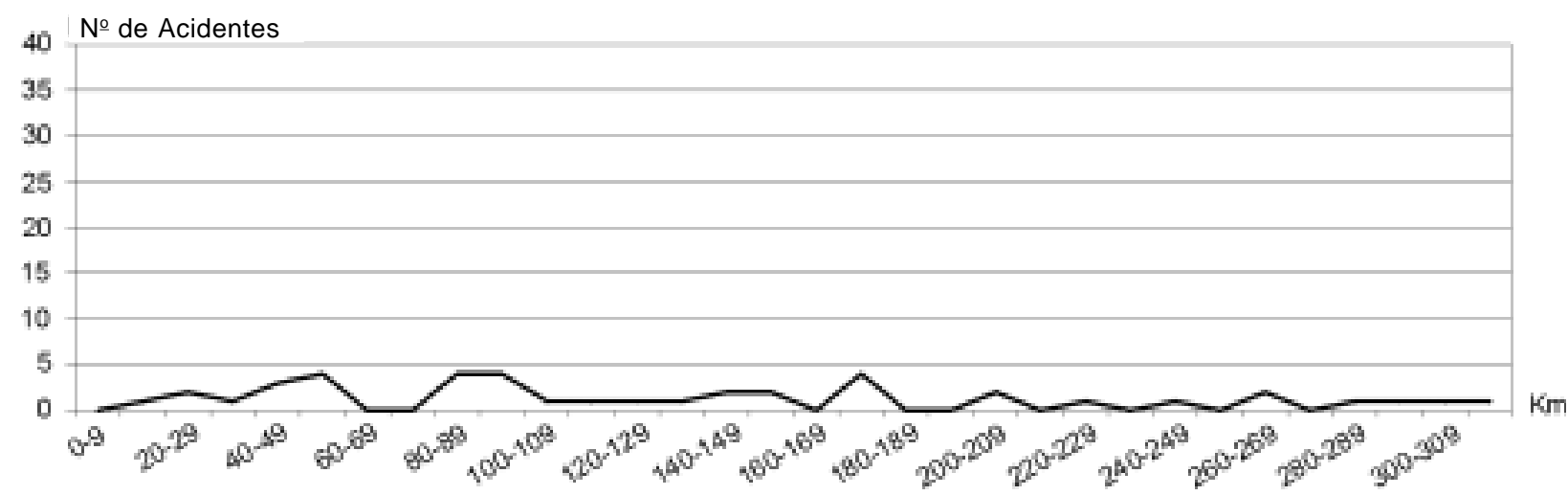


dente envolvendo o transporte de produtos perigosos pode ter conseqüências calamitosas para a população local. A análise dos dados georreferenciados indicou que muitos desses acidentes ocorreram em trechos rodoviários que cortam as principais manchas urbanas do Estado de São Paulo. Ficou evidente a frequiência de acidentes em uma das regiões mais populosas do Estado, a Região de Campinas. A mancha urbana correspondente ao município de Campinas apresenta o maior número de ocorrências nos trechos rodoviários que cortam a cidade, mas foram registrados vários casos em outras manchas urbanas da mesma região, correspondentes aos municípios de Sumaré, Americana, Piracicaba, Limeira, etc. Situação semelhante se verifica nas vias que passam pelo município de Cubatão. O trecho da Via Anchieta, principal acesso à Refinaria de Cubatão para o transporte de produtos perigosos, localizado na Serra do Mar, apresenta maior concentração de acidentes. Muitos ocorreram, também, no interior das manchas urbanas dos municípios do $\mathrm{ABC}$ e da Baixada Santista. Os municípios de Cubatão e de São Bernardo do Campo são os que apresentam o maior número de ocorrências. Na mancha urbana da Grande São Paulo foram também assinalados os acidentes ocorridos nos trechos rodoviários correspondentes aos municípios de Diadema e São Caetano do
Sul. No litoral, aparecem os casos registrados em São Vicente, Santos e Guarujá.

Para se ter uma visão do conjunto dos casos no espaço geográfico paulista, as principais conseqüências desses acidentes (vazamentos, derramamentos, incêndios, explosões e outras) foram classificadas e representadas, segundo o município de ocorrência, no Mapa 1.

Outra informação muito relevante coletada pelo policiamento rodoviário estadual diz respeito ao acidente ter causado, ou não, danos ao meio ambiente. Esses dados foram relacionados com o município de ocorrência e apresentados no Mapa 2. Cabe ressaltar que é possível, no momento do preenchimento do formulário pelo policial rodoviário, que não houvesse, ainda, um conhecimento completo das reais dimensões da catástrofe e suas repercussões ambientais. Dessa forma, parece correto considerar que a identificação dos casos que causaram danos ao meio ambiente tende a subestimar o número real de casos.

\section{PERFIL DOS MOTORISTAS}

Com o objetivo de traçar o perfil socioeconômico da população ocupada e contribuinte na classe de condutores de transporte rodoviário de produtos perigosos (Clas-

\section{MAPA 1}

Acidentes no Transporte de Produtos Perigosos Ocorridos nas Rodovias Estaduais, segundo as Conseqüências Estado de São Paulo - 1997-99

Acidentes

Incêndio/explosão

Vazamento/derramamento

Outras conseqüências

Não houve acidente

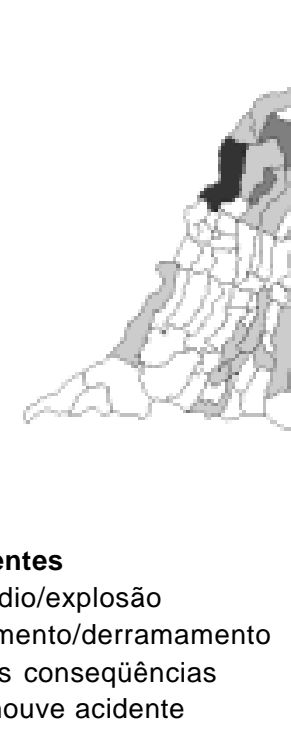

Fonte: Polícia Militar Rodoviária Estadual; Fundação Seade. 


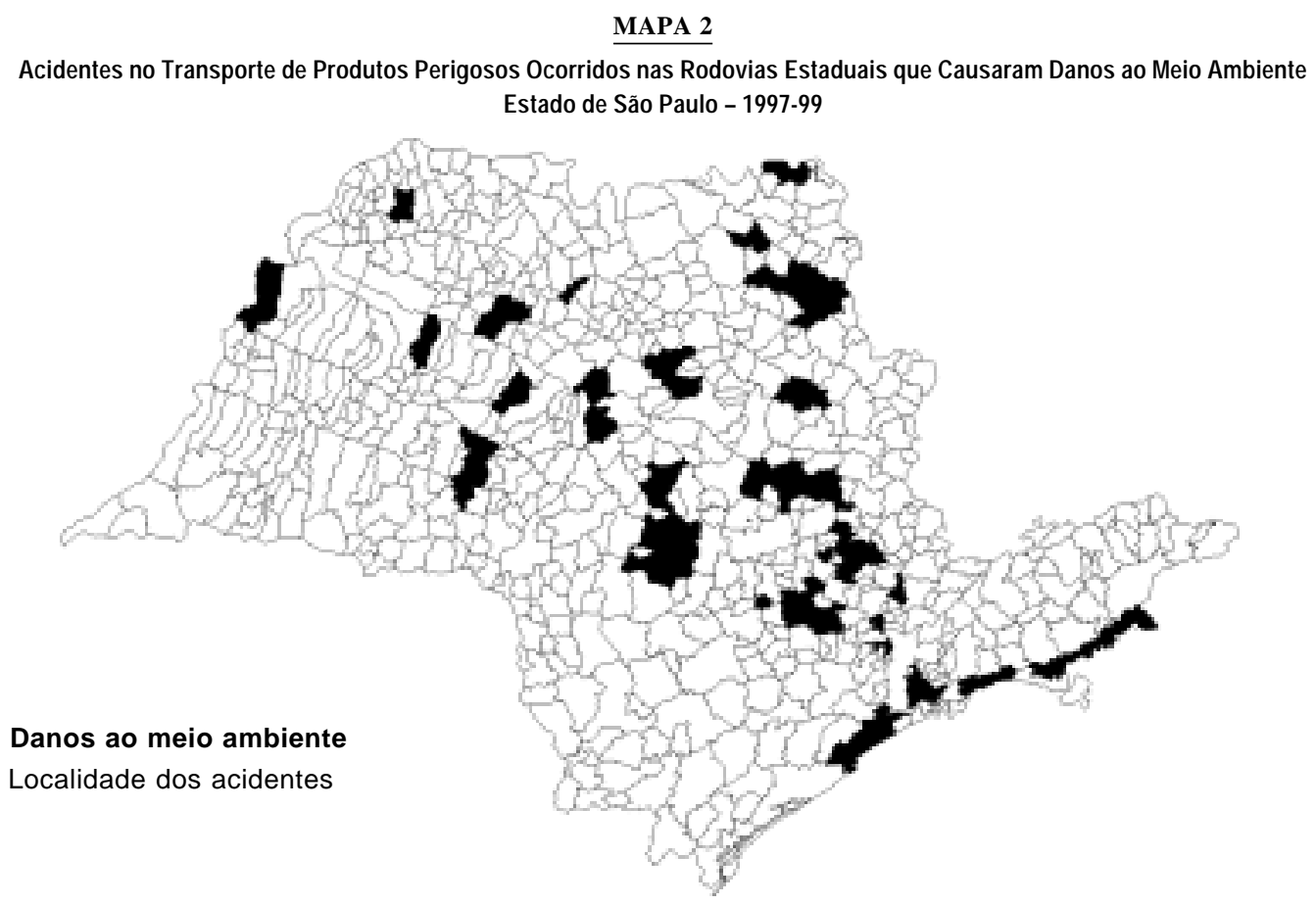

Fonte: Polícia Militar Rodoviária Estadual; Fundação Seade.

Nota: As informações sobre os danos ao meio ambiente não são coletadas pela Polícia Rodoviária Federal.

sificação Nacional de Atividade Econômica - CNAE 60.27-5), tomou-se como situação de referência os ocupados no transporte de cargas em geral (CNAE 60.26-7). Para tanto, recorreu-se às informações contidas em um registro administrativo do Ministério do Trabalho e Emprego: a Relação Anual de Informações Sociais - Rais. ${ }^{1}$ A partir desses registros elegeram-se alguns atributos, tais como idade, escolaridade, rendimento do trabalho e tamanho da empresa. A variável gênero foi eliminada pelo reduzido efetivo de mulheres nesse exercício profissional (menos de 0,5\%).

A distribuição etária mostra maior proporção de condutores com mais idade no transporte de carga de produtos perigosos do que naquele de cargas em geral, muito possivelmente pela exigência de critérios mais restritivos, como experiência prévia e maior tempo de serviço no exercício do transporte de cargas. Cerca de $71 \%$ dos motoristas de produtos perigosos têm idade na faixa de 30 a 49 anos, enquanto nas cargas em geral esse percentual é de $61 \%$. Da mesma forma, os motoristas menores de 30 anos representam cerca de $12 \%$ do total no primeiro caso e $29 \%$ no segundo.

Através das informações da Rais, verifica-se que o perfil profissional de condutores de produtos perigosos diferen- cia-se quanto ao rendimento do trabalho, cujo valor médio auferido por esta categoria profissional excede aquele percebido pelos condutores de cargas em geral $(6,5 \mathrm{e}$ 4,7 salários mínimos, respectivamente). A distribuição dos motoristas segundo a classe de rendimento, expresso em salários mínimos, demonstra que no caso dos produtos perigosos $65 \%$ dos trabalhadores recebem rendimentos acima de 5 salários mínimos, e nas cargas em geral esse percentual é de $29 \%$.

A escolaridade também apresenta diferença entre os dois contingentes, com um maior nível entre os transportadores de produtos perigosos. Verificou-se que $32 \%$ dos motoristas nesse ramo tinham até a quarta série completa, enquanto no caso das cargas em geral esse percentual foi de $25 \%$. A mesma vantagem foi verificada ao se considerar a proporção de motoristas com a oitava série completa (34\% e $26 \%$, respectivamente). Cabe ressaltar que no caso das cargas em geral, cerca de $10 \%$ dos motoristas tinham instrução inferior à quarta série e nos produtos perigosos esse percentual foi de $4 \%$. Tais resultados aparecem no Gráfico 3.

Quanto ao tamanho da empresa contratante, em volume de empregados, observa-se que as empresas que efetuam o transporte de cargas em geral são menores compa- 


\section{GRÁFICO 3}

Distribuição dos Condutores de Transporte Rodoviário de Cargas, por Tipo de Carga, segundo Nível de Instrução

Estado de São Paulo - 1998

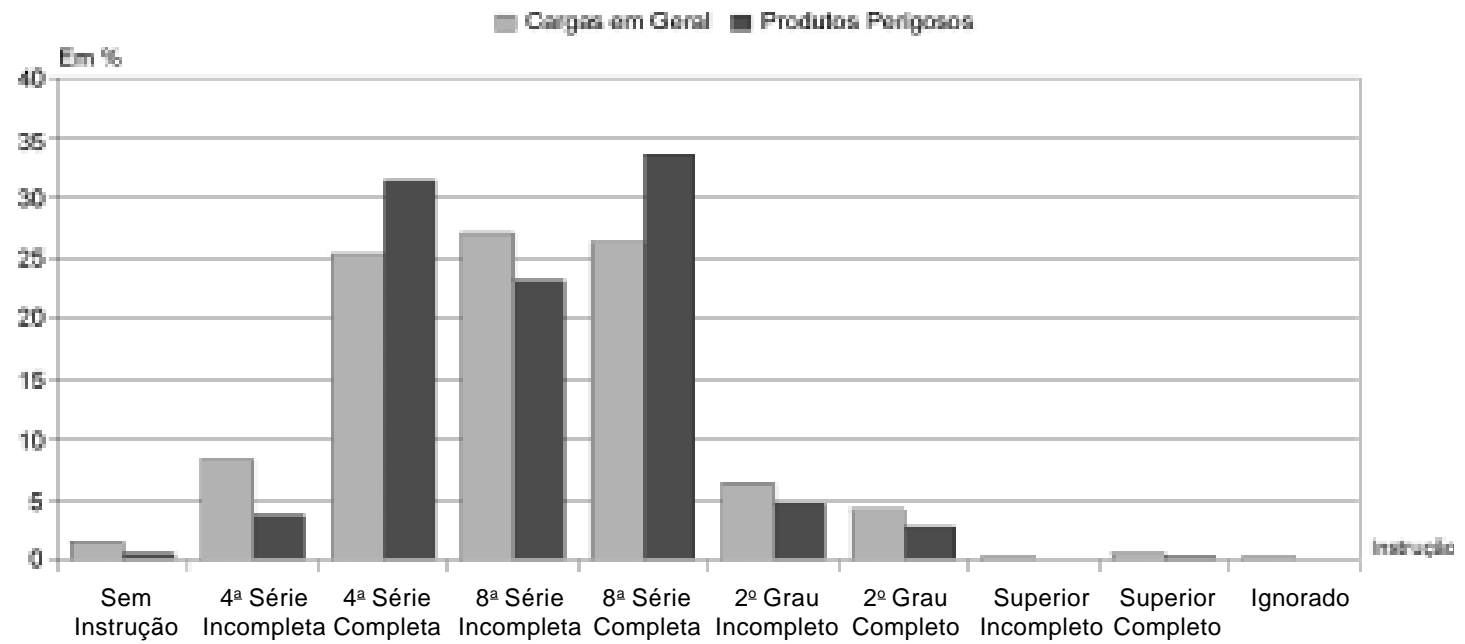

Fonte: Ministério do Trabalho. RAIS.

TABELA 3

Acidentes no Transporte de Produtos Perigosos, segundo o Horário do Acidente Estado de São Paulo - 1997-99

\begin{tabular}{|c|c|c|c|c|c|c|c|c|}
\hline \multirow{2}{*}{ Horário do Acidente } & \multicolumn{2}{|c|}{1997} & \multicolumn{2}{|c|}{1998} & \multicolumn{2}{|c|}{1999} & \multicolumn{2}{|c|}{ Total } \\
\hline & №s Absolutos & $\%$ & №s Absolutos & $\%$ & №s Absolutos & $\%$ & №s Absolutos & $\%$ \\
\hline Total & 487 & 100,00 & 510 & 100,00 & 566 & 100,00 & 1.563 & 100,00 \\
\hline Das 0 às $6 \mathrm{~h}$ & 71 & 14,58 & 82 & 16,08 & 96 & 16,96 & 249 & 15,93 \\
\hline Das 6 às $12 \mathrm{~h}$ & 124 & 25,46 & 152 & 29,8 & 142 & 25,09 & 418 & 26,74 \\
\hline Das 12 às $18 \mathrm{~h}$ & 165 & 33,88 & 154 & 30,2 & 188 & 33,22 & 507 & 32,44 \\
\hline Das 18 às $24 h$ & 127 & 26,08 & 122 & 23,92 & 140 & 24,73 & 389 & 24,89 \\
\hline Ignorado & 0 & - & 0 & - & 0 & - & 0 & - \\
\hline
\end{tabular}

Fonte: Polícia Militar Rodoviária Estadual.

rativamente àquelas dedicadas ao transporte de produtos perigosos. Observou-se que 55\% dos motoristas de produtos perigosos trabalhavam em empresas com mais de 50 funcionários; no caso das cargas em geral esse percentual foi de $36 \%$. Calculando-se o número médio de empregados para cada uma das categorias em questão, obteve-se para o transporte de produtos perigosos o número médio de 155 empregados, e para cargas em geral, de 93.

Em síntese, esses resultados apontam para um perfil diferenciado dos motoristas de veículos que transportam produtos perigosos em relação ao dos motoristas de cargas em geral, pois os primeiros apresentam maior nível de instrução, salário médio mais alto, idade média mais elevada e são contratados por empresas com maior número de empregados.

\section{CARACTERÍSTICAS DOS ACIDENTES}

Os acidentes se distribuem com maior intensidade nos dias úteis da semana, observando-se uma pequena concentração na sexta-feira. De modo geral, o domingo apresenta a menor freqüência de acidentes e o sábado situa-se numa posição intermediária.

De acordo com o horário da ocorrência, a distribuição dos acidentes, em grupos de seis horas, mostra claramente a pre- 
TABELA 4

Acidentes no Transporte de Produtos Perigosos, segundo as Condições da Pista

Estado de São Paulo - 1997-99

\begin{tabular}{|c|c|c|c|c|c|c|c|c|}
\hline \multirow{2}{*}{ Condições da Pista } & \multicolumn{2}{|c|}{1997} & \multicolumn{2}{|c|}{1998} & \multicolumn{2}{|c|}{1999} & \multicolumn{2}{|c|}{ Total } \\
\hline & №s Absolutos & $\%$ & №s Absolutos & $\%$ & №s Absolutos & $\%$ & №s Absolutos & $\%$ \\
\hline Total & 487 & 100,00 & 510 & 100,00 & 566 & 100,00 & 1.563 & 100,00 \\
\hline Seca & 361 & 74,13 & 377 & 73,92 & 458 & 80,92 & 1.196 & 76,52 \\
\hline Neblina & 6 & 1,23 & 9 & 1,76 & 9 & 1,59 & 24 & 1,54 \\
\hline Molhada & 106 & 21,77 & 114 & 22,35 & 92 & 16,25 & 312 & 19,96 \\
\hline Enlameada & 0 & - & 1 & 0,2 & 0 & - & 1 & 0,06 \\
\hline Ignorado & 14 & 2,87 & 9 & 1,76 & 7 & 1,24 & 30 & 1,92 \\
\hline
\end{tabular}

Fonte: Polícia Militar Rodoviária Estadual.

dominância do grupo das 12 horas às 18 horas, com maior incidência no intervalo entre 16 horas e 18 horas.

A proporção de vítimas em acidentes nas rodovias com pista simples $(37,2 \%)$ é maior do que naqueles ocorridos em rodovias com pista dupla $(28,5 \%)$. A maioria dos acidentes ocorreu em trechos sem a presença de faixa adicional $(84 \%)$, e somente $12,5 \%$, naqueles com existência dessa faixa. A faixa adicional nas estradas constitui um fator de maior segurança para os condutores de veículos, sobretudo nos trechos que apresentam maior dificuldade de tráfego. A grande concentração de acidentes nos locais sem faixa adicional, portanto, pode ser uma evidência da sua importância na redução dos acidentes.

A maior parte dos acidentes ocorreu em condições de pista seca $(76,52 \%)$, vindo a seguir os acidentes em pista molhada $(19,96 \%)$ e os demais, em condições de pista com neblina, enlameada ou ignorada $(3,52 \%)$. É evidente que esses fatores de risco atuam sobre a segurança nas estradas, mas a grande concentração de acidentes em pista seca sugere a interferência de outras causas.

\section{ACIDENTES GRAVES E FATAIS}

Foram registrados, pela Polícia Rodoviária, 83 acidentes graves e fatais de motoristas que transportam produtos perigosos nas rodovias estaduais, durante o período de 1997 a 1999.

Desse total, 34 foram fatais e 49 considerados graves, com o risco de ter ocorrido o óbito posteriormente. Cabe assinalar que, para se conhecer o número real de mortes, há necessidade de se recorrer a outro recurso metodológico, de vinculação de fontes de dados distintas (ocorrências policiais e declarações de óbitos), o que transcende os limites da atual pesquisa.
As maiores freqüências de casos de acidentes graves e fatais ocorreram nas Rodovias SP 310 (Washington Luiz) e SP 330 (Anhangüera), com respectivamente 14 e 11 casos no período mencionado. Em seguida, aparecem as Rodovias SP 304 e SP 65, com cinco casos registrados em cada uma. Apesar de a Rodovia SP 332 (General Milton Tavares de Souza) apresentar a segunda maior freqüência de acidentes, a proporção dos graves e fatais $(2,33 \%)$ é relativamente reduzida. Na Washington Luiz e na Anhangüera, esse valor correspondeu a $12,50 \%$ e a $4,93 \%$, respectivamente.

De modo geral, os acidentes mais graves para os motoristas são aqueles associados ao capotamento do veículo, quando o risco de acidentes graves e fatais é da ordem de 17,33\% dos casos. Quanto às conseqüências do acidente, como era de se esperar, as maiores proporções de casos graves e fatais correspondem a incêndio/explosão $(19,05 \%)$ e derramamento de produto químico (18,53\%).

Os dados coletados possibilitam também uma associação entre gravidade do acidente e idade do condutor do veículo. Verifica-se que as maiores proporções de acidentes graves e fatais ocorreram com motoristas nas faixas etárias de 15 a 29 anos e 50 anos e mais. Provavelmente a inexperiência dos mais jovens, agravada pela existência de um mercado de certificados ilícitos de capacitação técnica para o transporte de produtos perigosos, deve contribuir para essas evidências. $\mathrm{Na}$ faixa etária extrema superior, pode-se considerar as possíveis conseqüências de uma idade biológica que apresenta mais limitações diante do elevado estresse da ocupação e das sobrecargas do trabalho.

Evidentemente, todas essas observações necessitam de uma análise mais detalhada, dentro de um modelo estatístico mais complexo, que relacione todas as variáveis dis- 
poníveis simultaneamente e controle as interações e interferências entre variáveis. Trata-se de um recurso metodológico que ultrapassa os limites da análise exploratória atual.

\section{ACIDENTES DO TRABALHO}

Uma outra importante fonte de dados sobre acidentes de motoristas é a Comunicação de Acidentes do Trabalho (CAT), do Instituto Nacional de Seguridade Social (INSS). É por meio da CAT que se dá início ao processo de acidente do trabalho com o objetivo de estabelecer a causalidade entre acidente e trabalho, e de permitir a concessão dos benefícios ao trabalhador. As CATs são ricas em informações demográficas/sociais e possibilitam a identificação dos acidentes com motoristas de veículos que transportam produtos perigosos por intermédio dos códigos da CNAE (Classificação Nacional de Atividade Econômica) e da CBO (Classificação Brasileira de Ocupações). Os dados aqui analisados são os resultados do projeto "Pesquisa de Acidentes do Trabalho de Motoristas e Cobradores, através das Informações Detalhadas das CATs", desenvolvida na Fundação Seade em parceria com a Fundacentro.

A pesquisa no INSS identificou 49 processos de acidente do trabalho, inclusive fatais, relacionados com o transporte de produtos perigosos relativos às ocorrências do período de 1997 a 1999. Observa-se que todos os casos envolveram trabalhadores homens, sendo $73,47 \%$ casados, $16,33 \%$ solteiros, $4,08 \%$ divorciados ou separados. As maiores frequiências de casos do INSS ocorreram nas faixas etárias de 40-44 anos (26,53\%) e de 35-39 anos $(22,45 \%)$. Grande parte dos acidentes $(75,50 \%)$ ocorreu com trabalhadores de mais de 35 anos de idade.

Os resultados também indicam que, do total de acidentes sofridos pelos trabalhadores, $10,20 \%$ não provocaram afastamento do trabalhador de suas atividades profissionais e $36,73 \%$ determinaram afastamento de menos de 15 dias. Cabe destacar que $51,01 \%$ dos acidentes foram responsáveis por afastamentos de mais de 15 dias e menos de três meses. A comparação desse padrão de afastamento com aquele relativo ao total da categoria de motoristas e cobradores revelou uma grande semelhança entre os dois padrões de afastamentos, demonstrando que a atividade no transporte de produtos perigosos não é responsável por afastamentos significativamente mais longos que os verificados para o total da categoria de motoristas e cobradores.

\section{GRÁFICO 4}

Acidente do Trabalho de Motoristas de Caminhão e Similares de Produtos Perigosos, segundo Hora do Acidente Estado de São Paulo - 1997/1999

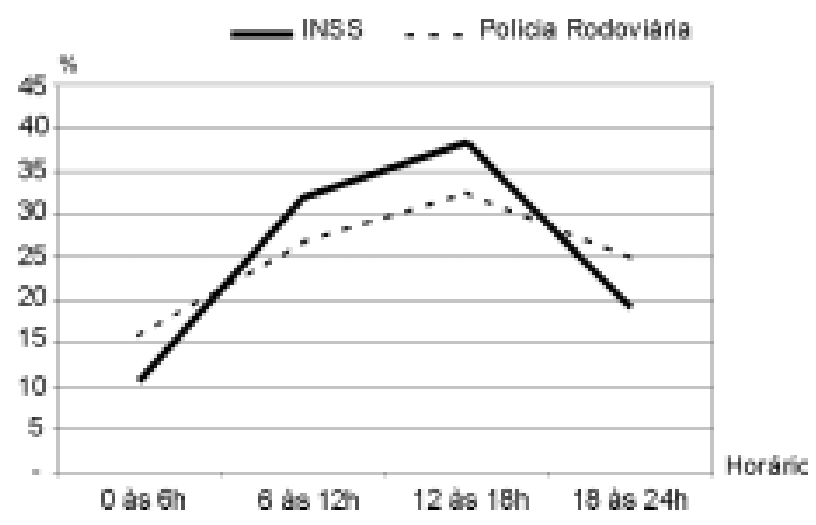

Fonte: Fundação Seade; INSS; Fundacentro/MTE; Denatran/MJ. Polícia Militar Rodoviária Estadual.

TABELA 5

Acidente do Trabalho de Motoristas de Caminhão e Similares de Produtos Perigosos, segundo Município da Empresa Estado de São Paulo - 1997-99

\begin{tabular}{lcr}
\hline Município da Empresa & Casos & $\%$ \\
\hline Total & 49 & 100,00 \\
Paulínia & 15 & 30,61 \\
São Paulo & 13 & 26,53 \\
São Bernardo do Campo & 5 & 10,2 \\
Araraquara & 3 & 6,12 \\
São José dos Campos & 3 & 6,12 \\
Bauru & 2 & 4,08 \\
Santo André & 2 & 4,08 \\
Campinas & 1 & 2,04 \\
Mirassol & 1 & 2,04 \\
Ribeirão Preto & 1 & 2,04 \\
Santos & 1 & 2,04 \\
Município do Estado do Paraná & 1 & 2,04 \\
Ignorado & 1 & 2,04 \\
\hline
\end{tabular}

Fonte: Fundação Seade; INSS; Fundacentro/MTE; Denatran/MJ.

Outro aspecto apresentado pela pesquisa é o da freqüência de acidentes segundo o horário da ocorrência. A curva construída com esses dados, que aparece na Gráfico 4, deixa evidente a ocorrência de maior concentração de acidentes no período da tarde, com redução à noite e no horário do almoço. Esse padrão se aproxima daquele correspondente ao da distribuição dos acidentes registrados pela Polícia Rodoviária Estadual. 
Os dados do INSS informam, também, sobre o município de ocorrência do acidente, o município de residência do trabalhador e o município da empresa transportadora. Os municípios que concentraram mais acidentes foram São Paulo, Paulínia e São Bernardo do Campo, e os municípios de residência mais frequientes foram São Paulo, Cosmópolis, Campinas e Paulínia. Os municípios-sede das empresas transportadoras mais citados foram Paulínia, São Paulo e São Bernardo do Campo, tal como se observa na Tabela 5.

\section{CONSIDERAÇÕES FINAIS}

As principais causas de acidentes com produtos perigosos foram atribuídas pela Polícia Rodoviária Estadual a erros do condutor (44,3\% do total dos acidentes), vindo em seguida a categoria outros $(23,61 \%)$, falhas com o veículo $(21,83 \%)$ e condições da via $(3,71 \%)$. A Polícia Rodoviária Federal também dá mais ênfase aos erros do condutor, sendo falta de atenção, excesso de velocidade e desobediência à sinalização os principais fatores envolvidos. Esses indicadores nos remetem à questão da educação para o trânsito e à importância do treinamento e capacitação para conduzir veículos transportando produtos perigosos. Embora esse último represente uma exigência legal para transportar tal tipo de produto, chama a atenção o fato de existirem casos de condutores de veículos acidentados com certificados de capacitação vencidos ou, até mesmo, sem portar nenhum certificado. Da mesma forma, essas estatísticas também revelam ocorrências com veículos sem equipamento de proteção individual, sem conjunto de emergência e sem extintor, significando que existe um número ainda maior de condutores de veículos operando em condições irregulares. Embora reduzidas em termos percentuais, essas situações irregulares podem ser a parte visível de uma problemática maior associada às condições reais de trabalho e ao padrão de educação e capacitação técnica dos condutores.

A outra causa que se destaca nas estatísticas da Polícia Rodoviária relaciona-se a falhas do veículo, colocando em questão as condições da frota de veículos de transporte de produtos perigosos no que diz respeito à idade média da frota e a seu grau de atualização tecnológica. Certamente, as implicações das limitações tecnológicas e falhas mecânicas, tratando-se de transporte de produtos perigosos, podem ter conseqüencias devastadoras sobre a população e o meio ambiente.

Quanto às condições das vias, aparece com a menor frequiência nas estatísticas do Estado de São Paulo, mas se sobressai quando analisada regionalmente ou por trechos de rodovia. Assim, por exemplo, ao serem considerados somente os acidentes da SP 332 (General Milton Tavares de Souza), a causa "via" passa a ser mencionada com uma freqüência duas vezes maior que na média do Estado. Ao se levar em conta também a informação sobre a qualidade da "sinalização", a categoria "regular e ruim", que atingiu $17 \%$ na média do Estado, passou para $71 \%$ na Rodovia SP 332. Esse exemplo não é um caso isolado e representa um indicador de que muitas vias não estão adequadas ao tráfego, faltando condições apropriadas de sinalização e outros itens de segurança da rodovia.

A utilização de instrumentos de análise georreferenciados possibilitou o monitoramento dos acidentes e a análise de sua distribuição espacial, levando-se em conta a malha rodoviária do Estado, as divisões administrativas, as concentrações populacionais urbanas, etc. Foram identificados os principais pontos de concentração de acidentes do Estado, que poderão ser objeto de análises mais detalhadas em estudos específicos posteriores. Os pontos de concentração estão associados à confluência de rotas de transporte de produtos perigosos com as principais rotas de outros tipos de transporte ou de veículos de passeio, elevando significativamente a ocupação do espaço rodoviário nesses locais e, conseqüentemente, o risco de acidentes. A localização de diversos pólos químicos e petroquímicos nas regiões metropolitanas de Campinas, da Grande São Paulo e da Baixada Santista, que constituem a maior concentração populacional do país, requer um cuidado especial no traçado das rotas de transporte para produtos perigosos que reduza os riscos de acidentes e suas conseqüências sobre a população e o ambiente. Trata-se de uma tarefa que se torna cada vez mais difícil diante da defasagem entre a infra-estrutura rodoviária necessária ao aumento do tráfego e às condições atuais das rodovias.

Os resultados da metodologia utilizada para mapear os acidentes podem ser úteis para subsidiar estudos de redimensionamento de demanda, identificação de pontos críticos e análise de rotas alternativas para o transporte de produtos perigosos.

Este trabalho, evidentemente, não esgota o tema, mas propicia um panorama diversificado da problemática dos acidentes rodoviários que ocorrem no transporte de produtos perigosos no Estado de São Paulo e sugere procedimentos metodológicos que podem contribuir nas atividades de monitoramento e prevenção de tais acidentes. 


\section{NOTA}

1. A relação Anual de Informações Sociais - Rais é um registro administrativo, de âmbito nacional, com periodicidade anual, obrigatório para todos os estabelecimentos, inclusive aqueles sem ocorrência de vínculos empregatícios no exercício, tendo esse tipo de declaração a denominação de Rais Negativa.

\section{REFERÊNCIAS BIBLIOGRÁFICAS}

ABIQUIM, Departamento Técnico. Comissão de Transportes. Manual para atendimento de emergências com produtos perigosos. 3 . ed. São Paulo, 1999. 234p.

FUZETTI, R.V. O poder público municipal e o transporte rodoviário de produtos perigosos no município de São Paulo. 2000. Dissertação (Mestrado) - Universidade de São Paulo, São Paulo, 2000.

RAMOS, F.B. Metodologia para escolha de alternativas de rotas para o transporte de materiais perigosos. 1997. Dissertação
(Mestrado) - Universidade Federal de Santa Catarina, Florianópolis, 1997.

SÃo PAULO (Estado). Assembléia Legislativa de São Paulo. Cadernos do Fórum São Paulo Século XXI. Diário Oficial do Estado de São Paulo, 110 (107/109), jun. 2000. Suplemento.

Secretaria de Segurança Pública. O que você deve saber sobre produtos perigosos. Disponível em:

< www.polmil.gov.br/unidades/cprv >. Acesso em: maio 2002. [site da Polícia Militar Rodoviária do Estado de São Paulo].

ZHANG, J. et al. Padrões etários de fatores relacionados a acidentes de tráfego fatais: enfoque sobre motoristas jovens e idosos. Revista da Associação Brasileira de Acidentes e Medicina de Tráfego, São Paulo, n.35, maio/jun. 2000.

Carlos Eugenio de Carvalho Ferreira: Pesquisador da Fundação Seade (ceugenio@seade.gov.br). 